\section{Review}

https://doi.org/10.1631/jzus.B2100344
Check for updates

\title{
Application of extracorporeal therapies in critically ill COVID-19 patients
}

\author{
Zhifeng ZHOU ${ }^{1 凶}$, Huang KUANG ${ }^{2}$, Yuexian $\mathrm{MA}^{3}$, Ling ZHANG ${ }^{1 凶}$ \\ ${ }^{1}$ Department of Nephrology, Kidney Research Institute, West China Hospital, Sichuan University, Chengdu 610041, China \\ ${ }^{2}$ Renal Division, Peking University First Hospital, Peking University Institute of Nephrology, Key Laboratory of Renal Disease, Ministry of \\ Health of China, Beijing 100034, China \\ ${ }^{3}$ Department of Nephrology, Hospital of Chengdu University of Traditional Chinese Medicine, Chengdu 610072, China
}

\begin{abstract}
The coronavirus disease 2019 (COVID-19) pandemic is a major public health event caused by severe acute respiratory syndrome coronavirus 2 (SARS-CoV-2). COVID-19 has spread widely all over the world. A high proportion of patients become severely or critically ill, and suffer high mortality due to respiratory failure and multiple organ dysfunction. Therefore, providing timely and effective treatment for critically ill patients is essential to reduce overall mortality. Convalescent plasma therapy and pharmacological treatments, such as aerosol inhalation of interferon- $\alpha$ (IFN- $\alpha$ ), corticosteroids, and tocilizumab, have all been applied in clinical practice; however, their effects remain controversial. Recent studies have shown that extracorporeal therapies might have a potential role in treating critically ill COVID-19 patients. In this review, we examine the application of continuous renal replacement therapy (CRRT), therapeutic plasma exchange (TPE), hemoadsorption (HA), extracorporeal membrane oxygenation (ECMO), and extracorporeal carbon dioxide removal $\left(\mathrm{ECCO}_{2} \mathrm{R}\right)$ in critically ill COVID-19 patients to provide support for the further diagnosis and treatment of COVID-19.
\end{abstract}

Key words: Coronavirus disease 2019 (COVID-19); Critical illness; Cytokine release syndrome (CRS); Acute kidney injury (AKI); Extracorporeal therapy

\section{Introduction}

At the end of 2019 , a new type of coronavirus pneumonia with unknown etiology spread rapidly throughout the world and presented a major threat to public health (Din and Boppana, 2020; Li L et al., 2020; Rothan and Byrareddy, 2020; Velavan and Meyer, 2020). On February 11, 2020, the World Health Organization (WHO) officially named this disease "coronavirus disease 2019 (COVID-19)." It was confirmed that it is caused by a new type of $\beta$ coronavirus (currently known as "severe acute respiratory syndrome coronavirus 2 (SARS-CoV-2)") (Lu et al., 2020; Shi et al., 2020). COVID-19 is a respiratory disease not only characterized

\footnotetext{
$\bowtie$ Ling ZHANG, zhangling_crrt@163.com Zhifeng ZHOU, zhouzf97@163.com

(iD) Ling ZHANG, https://orcid.org/0000-0003-1155-4802 Zhifeng ZHOU, https://orcid.org/0000-0003-3160-589X
}

Received Apr. 12, 2021; Revision accepted June 20, 2021; Crosschecked Aug. 17, 2021

(C) Zhejiang University Press 2021 by viral pneumonia, but in critically ill patients, also often associated with injury to multiple organs, such as the kidney, heart, blood, and nervous system (Azoulay et al., 2020). A large proportion of COVID-19 patients become severely or critically ill, and these patients have high mortality. A summary of 72314 cases of COVID-19 from China reported 14\% severely ill and 5\% critically ill patients, with a high fatality rate of $49 \%$ in the critical cases (Wu and McGoogan, 2020). In a multicenter retrospective study of 119 middle-aged COVID-19 patients, 18 (15.1\%) patients developed severe illness (Wang P et al., 2020). In a larger study of 1099 patients with COVID-19, Guan et al. (2020) reported $173(15.7 \%)$ severely and critically ill patients. In a retrospective cohort study (Nachtigall et al., 2020), 399/1860 (21.4\%) of COVID-19 patients were admitted to the intensive care unit (ICU), and 250/1850 (13.5\%) required invasive mechanical ventilation (IMV). Moreover, in some early reports of COVID-19 from China, the fatality rate of critically ill COVID-19 patients reached 52\%-62\% (Wu CM et al., 
2020; Yang XB et al., 2020; Zhou et al., 2020). Recent data from the USA show a fatality rate of $50 \%-67 \%$ among such patients (Bhatraju et al., 2020; Capone et al., 2020). Such high fatality rates seriously threaten human life and health. Therefore, there is an urgent need to find effective therapeutic strategies to reduce the mortality of critically ill COVID-19 patients.

Currently, there are many treatments for COVID-19 patients. Aerosol inhalation of interferon- $\alpha$ (IFN- $\alpha$ ) can be used for antiviral treatment (Jin et al., 2020). The early application of convalescent plasma therapy can reduce mortality (Mair-Jenkins et al., 2015). Immunosuppressants like tocilizumab can bind to both soluble interleukin-6 receptor (sIL-6R) and membranebound interleukin- 6 receptor (mIL-6R) to inhibit the release of interleukin-6 (IL-6). This may reduce the degree of inflammation in the body, thereby improving the clinical symptoms of patients (Zhao et al., 2020). However, these treatments are controversial and may not be effective when treating critically ill patients.

Recently, extracorporeal therapies have played a particularly important role in the treatment of critically ill COVID-19 patients. As adjuvant therapies for sepsis, extracorporeal therapies, such as therapeutic plasma exchange (TPE) and immunoadsorption (IA), can target cytokines and/or endotoxins and protect organ functions, and have been successively used in the treatment of critically ill patients (Yiğenoğlu et al., 2020). Extracorporeal therapies have also achieved certain effects in the treatment of COVID-19 patients, especially those who are critically ill. They are an effective measure to prevent organ failure and improve the survival rate of COVID-19 patients (Ronco et al., 2021). In this review, we discuss the application of extracorporeal therapies in critically ill COVID-19 patients to provide assistance for the further treatment of COVID-19.

\section{Characteristics of critical COVID-19}

When SARS-CoV-2 enters the nasal epithelial cells in the upper respiratory tract via angiotensin-converting enzyme 2 (ACE2), viral replication and local propagation occur, accompanied by a limited immune response (Hoffmann et al., 2020). Then, the virus invades and enters the type II pulmonary alveolar epithelial cells via ACE2, thereby causing a greater immune response with the release of inflammatory markers and many different cytokines (Wu et al., 2021). Continuing viral replication and infection of pulmonary alveolar epithelial cells leads to acute respiratory distress syndrome (ARDS) (Parasher, 2021). After viral infection, some patients progress to severe or critical illness. The WHO estimates that about 14\% of COVID-19 patients develop severe illness, and 5\% critical illness. The progression of disease in severe COVID-19 patients is usually rapid and there is no clear distinction between severe and critical illness. Combining these two classes might be helpful to diagnose and treat patients with intensive care in the early stages of critical illness (Li Q et al., 2020). According to diagnosis and treatment guidelines, severe patients manifest dyspnea, a respiratory rate of $\geqslant 30 \mathrm{~min}^{-1}$, blood oxygen saturation of $\leqslant 93 \%$, ratio of arterial oxygen partial pressure $\left(\mathrm{PaO}_{2}\right)$ to fractional inspired oxygen $\left(\mathrm{FiO}_{2}\right)$ of $<300$, and/or lung infiltrates of $>50 \%$ within 24 to $48 \mathrm{~h}$. Critical patients may present signs of respiratory failure requiring mechanical ventilation, septic shock, and/or multiple organ dysfunction or failure, requiring admission to ICUs (Wu and McGoogan, 2020).

\section{Cytokine release syndrome in COVID-19 patients}

Cytokine release syndrome (CRS), also known as a cytokine storm, is an excessive immune response of the host to viruses, bacteria, or other external stimuli, which is manifested by the uncontrolled release of inflammatory factors (Diamanti et al., 2020). CRS can transform COVID-19 patients from mild to severe, and from single organ damage to multiple organ dysfunction syndrome (MODS), which plays an important role in the pathological process of COVID-19 patients (Huang et al., 2020). However, some researchers now believe that COVID-19 patients do not have the characteristics of CRS. They have observed that the circulating cytokine levels of critically ill COVID-19 patients are lower than those of patients with bacterial sepsis or of other critically ill patients, which is not high enough to be regarded as a cytokine storm (Kox et al., 2020). However, SARS-CoV-2 infection can certainly lead to an uncontrolled immune function and a significant elevation of inflammatory cytokines such as C-reactive protein (CRP), IL-6, IL-10, monocyte chemoattractant protein-1 (MCP-1), and tumor necrosis factor- $\alpha$ (TNF- $\alpha)$. This may cause hemodynamic 
instability, shock, disseminated intravascular coagulation (DIC), and even MODS (García, 2020), all of which have obvious adverse effects on the healing of critically ill COVID-19 patients.

\section{Kidney damages in COVID-19 patients}

Variable degrees of kidney damage have been observed in substantial studies of critically ill COVID-19 patients. Acute kidney injury (AKI), hematuria, and proteinuria are common in COVID-19 patients (Smolander and Bruchfeld, 2020). Among 66 COVID-19 patients analyzed by $\mathrm{Na}$ et al. (2020), AKI patients accounted for $4.5 \%(3 / 66)$ of cases, and in the critically ill patients the serum creatinine, urine albumin to creatinine ratio (ACR), and urine protein to creatinine ratio (PCR) were significantly increased. In addition, Cheng et al. (2020) observed a prevalence of 5.1\% for AKI, $13.1 \%$ for elevated blood urea nitrogen, and $14.4 \%$ for elevated serum creatinine. Compared with patients with mild COVID-19, critically ill COVID-19 patients are more likely to develop AKI and have a significantly elevated serum creatinine (Na et al., 2020), which undoubtedly increases their mortality. Thus, we urgently need some effective treatment methods such as blood purification to reduce mortality.

However, the potential mechanisms by which kidney damage is induced by SARS-CoV-2 infection are still unclear. Based on most evidence, the following factors may be involved. First, the transmembrane protease serine 2 (TMPRSS2) expressed in renal tissue primes the spike (S) protein of SARS-CoV-2. This can promote the fusion of SARS-CoV-2 with renal cells (Dong et al., 2020), especially with proximal tubular epithelial cells (PTECs), by binding to the ACE2, thereby promoting the local replication of SARS-COV-2 and causing kidney damage (Menon et al., 2020). Second, immune activation and cytokine release can be induced by viral infection. Significantly elevated levels of CRP, TNF- $\alpha$, IFN- $\alpha$, IL-1, IL-6, and IL-12 in critically ill COVID-19 patients can lead to an uncontrolled systemic inflammatory response, which can cause increased renal vascular permeability and decreased effective circulation capacity, ultimately leading to kidney injury (Wu CM et al., 2020). Third, dehydration can lead to kidney insufficiency and contribute to acute tubular necrosis (Post et al., 2020). In addition, a genetic predisposition has been found to play a key role in the development of kidney damage. Collapsing glomerulopathy was found to be associated with high-risk apolipoprotein L1 (APOL1) variants in COVID-19 patients. Renal biopsy specimens from COVID-19 patients with a high-risk genotype APOL1 revealed glomerular collapse, extensive disappearance of foot processes, and focal/diffuse acute tubular injury (Wu HJ et al., 2020).

In critically ill COVID-19 patients, the levels of inflammatory cytokines are significantly increased, and the development of kidney damage is also common. Treatment with corticosteroids can alleviate the systemic inflammatory response in critically ill COVID-19 patients, thereby reducing the length of hospitalization and increasing the survival rate (Wang $Y$ et al., 2020). However, high doses and/or long-term use of corticosteroids can have a variety of adverse effects such as an increased risk of infection and metabolic disorders (Fardet and Fève, 2014). By targeting both sIL-6R and mIL-6R, tocilizumab can inhibit the IL-6 signaling pathway to reduce the inflammatory response, improve oxygenation, and reduce mortality. Despite these positive effects, the efficacy of treatment of COVID-19 with tocilizumab has not yet been fully established (Izda et al., 2021). However, as adjuvant therapies for sepsis, extracorporeal therapies might play a multifaceted role in improving this situation, and have been successfully applied in the treatment of critically ill COVID-19 patients and their complications.

\section{Continuous renal replacement therapy}

Continuous renal replacement therapy (CRRT) is a new type of blood purification technology that has been proven to be effective in the treatment of patients with severe Middle East respiratory syndrome (MERS) (Cha et al., 2015). Studies have shown that CRRT can treat critically ill COVID-19 patients by removing potentially damaging toxins and stabilizing their metabolic and hemodynamic status (Tandukar and Palevsky, 2019; Fu et al., 2020). In a retrospective case-series, the levels of CRP, IL-6 and D-dimer of 50 critically ill COVID-19 patients who underwent $2 \pm 1$ sessions of CRRT treatment significantly decreased, while their $\mathrm{PaO}_{2} / \mathrm{FiO}_{2}$ ratios and lymphocyte counts increased (Alharthy et al., 2021). Katagiri et al. (2021a) suggested that CRRT should also be considered for critically ill patients with severe AKI. They recommend CRRT 
treatment for patients in the acute phase of COVID-19 with AKI or MODS. Currently, various modalities of CRRT are available in the treatment of critically ill patients, including continuous veno-venous hemofiltration $(\mathrm{CVVH})$, continuous veno-venous hemodialysis (CVVHD), and continuous veno-venous hemodiafiltration (CVVHDF). CVVHD or CVVHDF is the preferred modality. CVVHD and CVVHDF modalities can both decrease the filtration fraction and reduce the risk of circuit clotting (Nadim et al., 2020). Different CRRT modes should be selected according to the purpose of the treatment. For example, when patients are in a hypercoagulable state or not undergo anticoagulation treatment, CVVHD or CVVHDF can be applied (Fayad et al., 2016). CVVHD is effective for solutes with small molecular weights such as urea, creatinine, and potassium. However, when it comes to the clearance of higher-molecular-weight solutes such as pro-inflammatory cytokines, CVVH could be a better choice than CVVHD (Tandukar and Palevsky, 2019). In addition, there is evidence indicating that CVVHD might be the preferred method to treat severe intoxications in hemodynamically unstable patients (Kade et al., 2020).

High-flux (HF) and high-cut-off (HCO) membranes have been combined with CRRT for cytokine removal in critically ill patients. A reduction of inflammatory response mediators can be observed with the use of $\mathrm{HF}$ and HCO membranes, thus improving oxygenation and reducing non-cardiogenic pulmonary edema in critically ill patients. In addition to small toxins, HF membranes have high clearance capacity for middle-sized molecules such as $\beta 2$-microglobulin to prevent dialysis-related amyloidosis, which makes it a more efficient treatment than low-flow (LF) membranes (Weidhase et al., 2019). Compared with standard CRRT, some studies indicated that HCO membranes can decrease the length of stay in ICU, vasopressor days, and ICU mortality, and attenuate plasma levels of inflammatory mediators such as IL-6, IL-8, and TNF- $\alpha$ (Haase et al., 2007; Villa et al., 2017). However, the efficacy of HCO membranes remains controversial. Some researchers are skeptical about the roles of HCO membranes in critically ill patients, as they have not observed additional beneficial effects in reducing hospital duration or mortality in these patients (Atan et al., 2018). In addition, whether HCO membranes could achieve greater success than HF membranes in treating critical patients is still unclear. Therefore, it is vitally important to design more high-quality studies to evaluate the safety and efficacy of HCO membranes in treating critically ill patients.

It is equally critical to establish the timing and treatment dose of CRRT in critically ill COVID-19 patients, which is relevant to their prognosis. Currently, there is no uniform standard for the timing of CRRT treatment in critically ill COVID-19 patients. Some clinical studies showed that the early application of CRRT is conducive to improving the prognosis and reducing mortality. The timing of early CRRT treatment was defined to be within $72 \mathrm{~h}$ of the onset of the disease. Beyond $72 \mathrm{~h}$, the cytokine cascade reaction begins, which makes it difficult to block the inflammatory response and improve the prognosis (Pan et al., 2020). The ELAIN randomized clinical trial (RCT) also indicated that early implementation of CRRT in critically ill patients with AKI showed a significantly lower mortality rate within $90 \mathrm{~d}$ (Zarbock et al., 2016). However, in COVID-19 patients with AKI, some researchers considered that the timing of initiating CRRT should be individualized, considering the stage of $\mathrm{AKI}$, the degree of kidney function, and the clinical context. In terms of treatment dose, an early prospective randomized study claimed that a high-volume hemofiltration (ultrafiltration rate of $45 \mathrm{~mL} /(\mathrm{kg} \cdot \mathrm{h})$ ) can improve the prognosis of patients with severe AKI (Ronco et al., 2002). In a recent RCT including 82 patients, early high-volume hemofiltration (ultrafiltration rate of $65 \mathrm{~mL} /(\mathrm{kg} \cdot \mathrm{h}))$ decreased the incidence of sepsis and mortality in patients with severe burns (You et al., 2018). However, in a multi-center RCT involving septic patients, high-volume hemofiltration (ultrafiltration rate of $70 \mathrm{~mL} /(\mathrm{kg} \cdot \mathrm{h}))$ did not improve the prognosis in patients with severe AKI compared with conventional volume hemofiltration (ultrafiltration rate of $35 \mathrm{~mL} /(\mathrm{kg} \cdot \mathrm{h})$ ). Moreover, the $28-\mathrm{d}$ mortality in patients with sepsis could not be improved with an ultrafiltration rate of $70 \mathrm{~mL} /(\mathrm{kg} \cdot \mathrm{h})$ (Joannes-Boyau et al., 2013). Several prospective RCTs involving patients with sepsis also showed no advantages of a higher dose (ultrafiltration rates of $35-40 \mathrm{~mL} /(\mathrm{kg} \cdot \mathrm{h})$ ) (The VA/NIH Acute Renal Failure Trial Network, 2008; The RENAL Replacement Therapy Study Investigators, 2009). Therefore, better large multicenter RCTs are still needed to determine the optimal treatment dose of CRRT for critically ill COVID-19 patients.

In addition to conventional CRRT treatment, combination with other treatment modalities can provide 
better multi-organ support in the treatment of critically ill COVID-19 patients. Extracorporeal membrane oxygenation (ECMO) is a last line of defense for critically ill COVID-19 patients with severe hypoxia; however, evidence has shown that it may promote the release of cytokines and aggravate the inflammatory state of patients (Al-Fares et al., 2019). As mentioned above, CRRT can remove inflammatory factors. Thus, combined ECMO/CRRT support may be an effective therapy for these patients. In several critically ill COVID-19 patients treated with combined ECMO/ CRRT support, the levels of inflammatory factors were significantly reduced, and computed tomography (CT) scans showed a significant decrease in ground-glass opacity (Zou and Li, 2020). This also indicated that the option of combined ECMO/CRRT support might be promising for the treatment of critically ill COVID-19 patients. CRRT combined with plasma exchange (Lin et al., 2020) or hemoperfusion (HP) (Dastan et al., 2020) can also provide life support to COVID-19 patients.

CRRT is the most common treatment for COVID-19 patients, but in many hospitals CRRT resources are in short supply. Therefore, making more effective use of limited CRRT resources will become particularly important. The use of increased doses of unfractionated heparin (UFH) or the combination of regional citrate anticoagulation (RCA) and heparin can prevent premature filter clotting, thereby prolonging filter life (Attallah et al., 2021; Deep et al., 2021). Recently, a prospective observational cohort study demonstrated that the combination of RCA and heparin may be better than the application of heparin or citrate alone. In this study, an increase of at least $165 \%$ in the median circuit survival was observed when applying the combination of RCA and heparin, which greatly improved the survival rate of the filter (Volbeda et al., 2020). Optimizing vascular access can conserve resources by minimizing the risk of catheter-related infection and thrombosis, and providing sufficient uninterrupted blood flow for CRRT (Chua et al., 2020). In addition, CRRT resources can be made more efficient by reducing the intensity of CRRT to conserve fluid, and lowering the blood flow to reduce the consumption of citrate (Adapa et al., 2020). Some studies have shown that prolonged intermittent renal replacement therapy (PIRRT) in the treatment of some critically ill COVID-19 patients can also prolong their survival rate (Yang Y et al., 2020; Ramirez-Sandoval et al., 2021). Although transitory intradialytic hypotension might occur, this treatment can greatly increase patients' coverage of CRRT machines (Yessayan et al., 2021).

In conclusion, CRRT might have the potential to improve the symptoms and prognosis of critically ill COVID-19 patients. However, there are some conflicting opinions and limitations. The determination of the optimal timing and dosing of CRRT in treating critically ill patients is still controversial, and large multicenter RCTs with better designs are urgently needed to address this problem. CRRT resources are in short supply, and therefore finding strategies to make the consumption of CRRT resources more effective is particularly important. The combination of RCA and heparin anticoagulation, optimizing vascular access, lowering the blood flow, and the use of PIRRT can all increase the coverage of CRRT.

\section{Therapeutic plasma exchange}

Plasma exchange is an extracorporeal blood purification technology that separates and removes the pathological plasma from the patient's blood, and simultaneously infuses a certain amount of solution or normal human plasma to eliminate pathogenic substances and reduce pathological damage (Grazioli et al., 2020). A growing number of studies have indicated that TPE might have potential benefits for some critically ill COVID-19 patients. Khamis et al. (2020) reported a study of 31 cases of COVID-19 patients. Among them, 11 patients were treated with TPE and compared with a non-TPE group. Patients on TPE had a higher extubation rate and lower all-cause mortality. Faqihi et al. (2020) enrolled ten ICU COVID-19 patients presenting with ARDS plus MODS. After TPE completion, the levels of CRP and IL-6 and organ function assessment scores tended to be normal. Moreover, following TPE treatment, all 14 critically ill COVID-19 patients requiring IMV showed improvement in symptoms and a decrease of inflammatory markers such as CRP and IL-6. Finally, ten patients were successfully liberated from IMV (Jaiswal et al., 2021).

TPE can remove inflammatory cytokines (Fernandez et al., 2020), stabilize the endothelial membrane, and reset the hypercoagulable state (Yiğenoğlu et al., 2020), and might have a unique role in the treatment of critically ill COVID-19 patients. Activation of the cytokine cascade plays an important role in the 
development of ARDS. TPE can decrease or even eliminate cytokines and inflammatory mediators to help reduce the inflammatory state of patients (Adeli et al., 2020). After receiving TPE treatment, the levels of IL-6 and CRP were significantly decreased, and clinical condition was obviously improved (Luo et al., 2020). However, while reducing the inflammatory state, TPE can also remove the neutralizing antibodies against SARS-CoV-2, which is unfavorable (Honore et al., 2020). There are some methods that may possibly solve this problem. Convalescent plasma carries specific neutralizing antibodies, and using TPE combined with convalescent plasma may be an effective and safe method (Shen et al., 2020; Stahl et al., 2020b; Jaiswal et al., 2021). However, a randomized controlled, openlabel, platform trial including 11558 COVID-19 patients showed no significant difference in improving survival rate or other clinical outcomes (RECOVERY Collaborative Group, 2021). Timely intravenous immunoglobulin (IVIG) treatment can also improve adverse clinical outcomes in critically ill COVID-19 patients after TPE treatment, and may be an effective therapeutic strategy (Pourahmad et al., 2020; Shi et al., 2020). Factors such as SARS-CoV-2-induced endothelial dysfunction, and microvascular and macrovascular thromboses are also critical in determining the clinical outcomes of COVID-19 patients (Varga et al., 2020). Obvious endothelial activation and blood hypercoagulability can be observed in critically ill COVID-19 patients, and are reflected by significantly increased von Willebrand factor (VWF) antigen and D-dimers levels. TPE can reduce the levels of both VWF and Ddimers, thereby improving the survival rate of the critically ill patients (Zachariah et al., 2020). Therefore, TPE could be used for the treatment of critically ill COVID-19 patients, especially those with marked endothelial activation and a high risk of thrombosis (Gucyetmez et al., 2020). Another advantage of TPE is that it can replace the protective factors consumed in the host's immune response against the virus, such as protein $\mathrm{C}$, a disintegrin and metalloproteinase with a thrombospondin type 1 motif, member 13 (ADAMTS13) (Stahl et al., 2020a), and angiopoietin-1 (Stahl et al., 2020b). These factors play a critical role in preventing vascular leakage and maintaining the microcirculatory flow.

However, TPE might also have some potential limitations in the treatment of critically ill COVID-19 patients. After TPE treatment, the production of cytokines continues, which could subsequently cause organ damage within a few minutes (Daoud et al., 2021). At this point, a strategy for blocking cytokines for a long time becomes particularly important. In addition, TPE treatment may cause hypocalcemia when replacing fluids, which will cause adverse reactions such as twitching of hands and feet and arrhythmia. Also, the reaction between the red blood cells of patients and the plasma of donors might cause anaphylactic shock (Adeli et al., 2020). Both hypocalcemia and anaphylactic shock can lead to death. Therefore, strict attention should be paid to these problems during the treatment of critically ill COVID-19 patients with TPE, and solutions should be actively sought in subsequent studies and practice.

In summary, TPE might be able to stabilize critically ill or rapidly deteriorating patients to reduce mortality by removing inflammatory cytokines, stabilizing the endothelial membrane, and resetting the hypercoagulable state. Future clinical studies should be designed to determine if TPE could be an alternative treatment to reduce hyperinflammation, hyper-viscosity, and hypercoagulability in critically ill COVID-19 patients. In addition, more effective strategies should be designed to address the negative consequences and limitations of TPE, such as the removal of potentially beneficial molecules.

\section{Hemoadsorption}

HP and continuous plasma filtration absorption (CPFA) are widely used in clinical practice for patients with critical illness. HP can remove cytokines, endotoxins, and other circulating inflammatory mediators to delay the hyper inflammation process, and has shown encouraging results in the treatment of septic shock (Berhés et al., 2020). Thus, HP might be another important treatment option for critically ill COVID-19 patients (Safari et al., 2020). Several case reports have reported COVID-19 patients who were hospitalized in ICUs and developed ARDS during their hospitalization, but whose clinical condition was improved significantly after HP treatment (Moradi and Abbasi, 2020; Rampino et al., 2020; Vardanjani et al., 2021). After HP treatment of some COVID-19 patients with $\mathrm{PaO}_{2} / \mathrm{FiO}_{2}$ ratio of $<300$, their respiratory symptoms improved and the severity of the disease decreased significantly (Katagiri et al., 2021b). Liver impairment has been reported in some 
critically ill COVID-19 patients. HP can eliminate the toxins associated with acute liver failure and has become an attractive treatment option for these patients (Colaneri et al., 2020). Punctual and early HP treatments can prevent the occurrence and development of ARDS, AKI, liver failure, and MODS, thereby stabilizing the patient's condition and reducing mortality (Vardanjani et al., 2021). IA is a well-tolerated and safe plasma adsorption therapy that can selectively remove endogenous medium and large molecular pathogenic substances such as cytokines, endotoxins, and activated neutrophils from the blood (Schefold et al., 2007). Although the theoretical basis for using IA in critically ill COVID-19 patients is still limited, many such patients have received IA treatment and achieved certain effects. The clinical application of IA was also pointed out by the expert consensus on the treatment of critically ill COVID-19 patients in China (Chinese Society of Nephrology, Professional Committee of Nephrology, 2020). CPFA is a new type of blood purification therapy, which can effectively remove cytokines from the blood and at the same time regulate the balance of volume and stabilize the body environment (Hazzard et al., 2015). Thus, CPFA may also be an effective method to improve the clinical symptoms of COVID-19 patients.

To summarize, hemoadsorption (HA) is applied to the adsorption and removal of inflammatory cytokines, and has achieved certain curative effects. HP has the potential to remove inflammatory cytokines, endotoxins, danger-associated molecular patterns (DAMPs), and pathogen-associated molecular patterns (PAMPs), and eliminate the toxins associated with acute liver failure. In addition to endotoxins and cytokines, IA could adsorb leukocytes, but evidence of its function in the treatment of critically ill COVID-19 patients is still limited. CPFA may also be an effective method for treating critically ill COVID-19 patients because of its ability to clear cytokines and stabilize the body environment.

\section{Extracorporeal membrane oxygenation}

As a technology providing effective circulation and respiratory support for critically ill patients, ECMO is helpful in improving blood perfusion, and gaining valuable time for the recovery of the cardiopulmonary system. Currently, venous to arterial (VA)-ECMO, venous to venous (VV)-ECMO, and venous to arterial and venous (VAV)-ECMO are the main modes (Napp et al., 2016). When there is respiratory failure, the VVECMO mode is preferred. VA-ECMO and VAV-ECMO modes can be used when both respiratory support and circulatory support are required (Camboni et al., 2019). ECMO plays a crucial role in life support for critically ill COVID-19 patients with cardiopulmonary failure. In the COVID-19 treatment guidelines of the National Health Commission of China (NHCC) and the National Institutes for Health (NIH), the use of ECMO can be regarded as a salvage treatment of respiratory support for severely and critically ill patients when conventional treatments fail (Ma et al., 2020). When IMV cannot solve hypoxemia, and measures such as muscle relaxants and prone position ventilation are still not effective, ECMO can be used in hospitals with conditions. However, there are some limitations in the current use of ECMO in COVID-19 patients. The benefits and risks of using ECMO in COVID-19 patients are still unclear. There have been successful cases of ECMO treatment of critically ill COVID-19 patients; however, the overall effect is not ideal, and the fatality rate can be as high as $82.3 \%(14 / 17)$ or $83.3 \%(5 / 6)$ (Ñamendys-Silva, 2020; Yang XB et al., 2020). Relevant clinical evidence on the use of ECMO in COVID-19 patients is scarce, and the timing, indications, management, benefits, and risks of ECMO are still controversial. Hence, high-quality RCTs are urgently needed to elaborate the efficacy and validity of using ECMO in critically ill COVID-19 patients.

\section{Extracorporeal carbon dioxide removal}

Extracorporeal carbon dioxide removal $\left(\mathrm{ECCO}_{2} \mathrm{R}\right)$ is a rescue therapy for critically ill COVID-19 patients. It can reduce the tidal volume and respiratory frequency to decrease the high peak airway pressure to limit ventilator-induced lung injury (VILI), and can also correct $\mathrm{CO}_{2}$ retention caused by ventilation defects (Combes et al., 2020). After receiving $\mathrm{ECCO}_{2} \mathrm{R}$ treatment, some critically ill COVID-19 patients with hypercapnia who were difficult to cure with conventional treatments were significantly improved to the extent that the extracorporeal life support (ECLS) was able to be weaned, and all were discharged from the ICU without any treatment-related adverse events (Husain-Syed et al., 2020; Tully et al., 2020). ECCO $R$ combined with CRRT may also be safe and feasible 
for COVID-19 patients with ARDS or AKI. Although CRRT alone may have the ability to remove $\mathrm{CO}_{2}$ (Jonckheer et al., 2019), the combination can remove the excess $\mathrm{CO}_{2}$ and at the same time compensate for respiratory acidosis, thereby further limiting respiratory pressure and promoting protective lung ventilation. Chen et al. (2021) reported two critical COVID-19 patients receiving $\mathrm{ECCO}_{2} \mathrm{R}$ combined with CRRT. After the treatment, their ventilator parameters such as tidal volume and positive end-expiratory pressure (PEEP) were down-regulated, and the incidence of VILI had decreased. Anticoagulation is necessary in this treatment. Heparin appears to be the anticoagulant most frequently used, but patients with heparin-infusion anticoagulation might experience membrane clotting before the end of the treatment. However, compared with heparin anticoagulation, the combination of regional citrate with a heparin anticoagulation strategy has the effect of enhancing membrane duration (Schmidt et al., 2018). Moreover, it is recommended to use CVVHD or CVVHDF for CRRT modalities, which can also reduce the filtration fraction and has a low risk of circuit clotting (Husain-Syed et al., 2020). However, the application of $\mathrm{ECCO}_{2} \mathrm{R}$ to treat patients with COVID-19 is still limited, and it is necessary to conduct more multi-center randomized trials to evaluate the impact of $\mathrm{ECCO}_{2} \mathrm{R}$ on the clinical outcomes of critically ill patients. Overall, the $\mathrm{ECCO}_{2} \mathrm{R}$ system makes it possible to obtain metabolic removal of $\mathrm{CO}_{2}$ to facilitate more protective ventilation. The combination of $\mathrm{ECCO}_{2} \mathrm{R}$ and CRRT might also be an option to efficiently treat critically ill COVID-19 patients. However, further highquality studies are needed due to the lack of relevant clinical evidence.

\section{Conclusions}

Critically ill COVID-19 patients can experience a high-inflammation status and variable degrees of kidney damage and even MODS. Based on the recent literature, extracorporeal therapies have a potential role in the treatment of critically ill COVID-19 patients (Table 1). Extracorporeal therapies can remove inflammatory cytokines and toxins, and provide support for multiple organs, which can significantly improve the clinical symptoms and reduce mortality. However, limitations still exist when treating critically ill COVID-19 patients (Table 2), and there is a lack of large-scale multicenter clinical studies to guide clinicians in the treatment of these patients. More studies are needed to clarify the roles of various types of extracorporeal therapies in the treatment of these patients. Currently, medical workers are required to formulate individualized extracorporeal treatment plans based on the specific clinical conditions of each patient (Fig. 1), so that extracorporeal therapies can become an effective and safe treatment method.

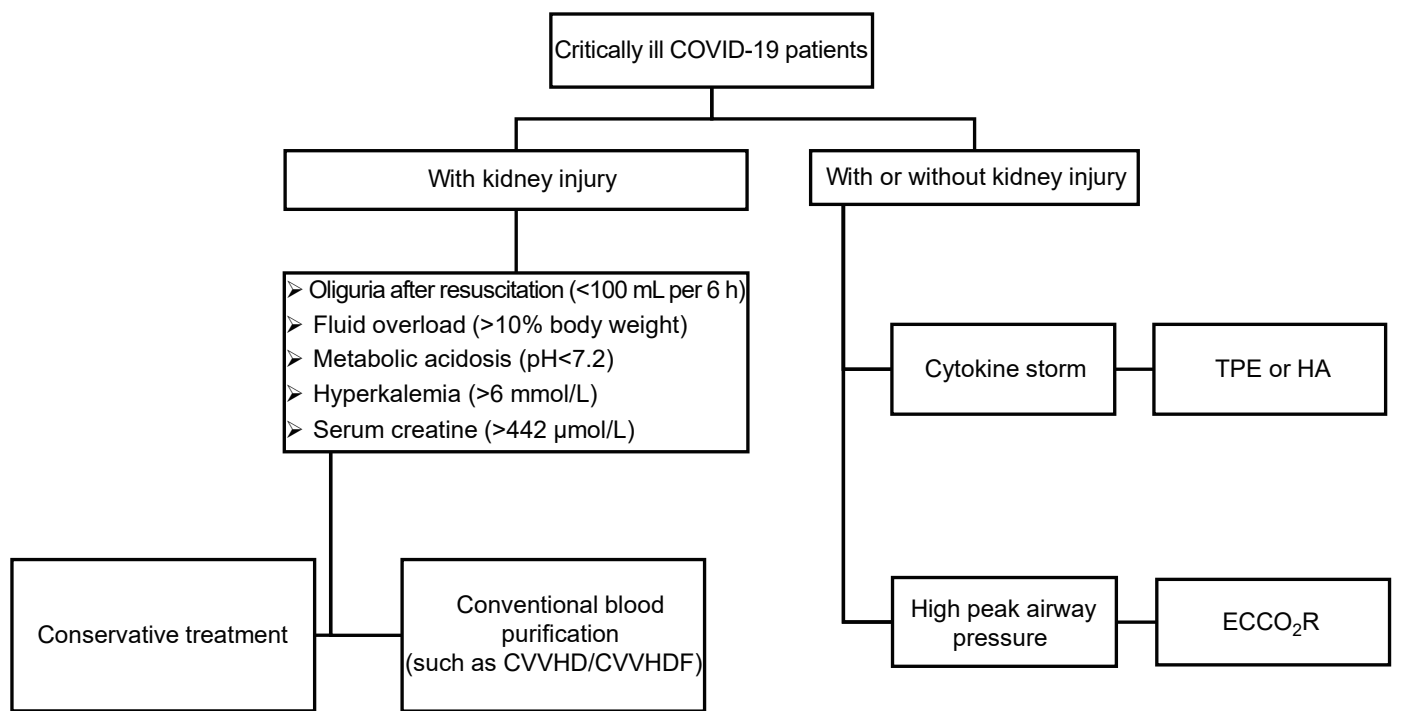

Fig. 1 Modality options of extracorporeal purification therapies for critically ill COVID-19 patients. COVID-19: coronavirus disease 2019; CVVHD: continuous veno-venous hemodialysis; CVVHDF: continuous veno-venous hemodiafiltration; TPE: therapeutic plasma exchange; $\mathrm{HA}$ : hemoadsorption; $\mathrm{ECCO}_{2} \mathrm{R}$ : extracorporeal carbon dioxide removal. 


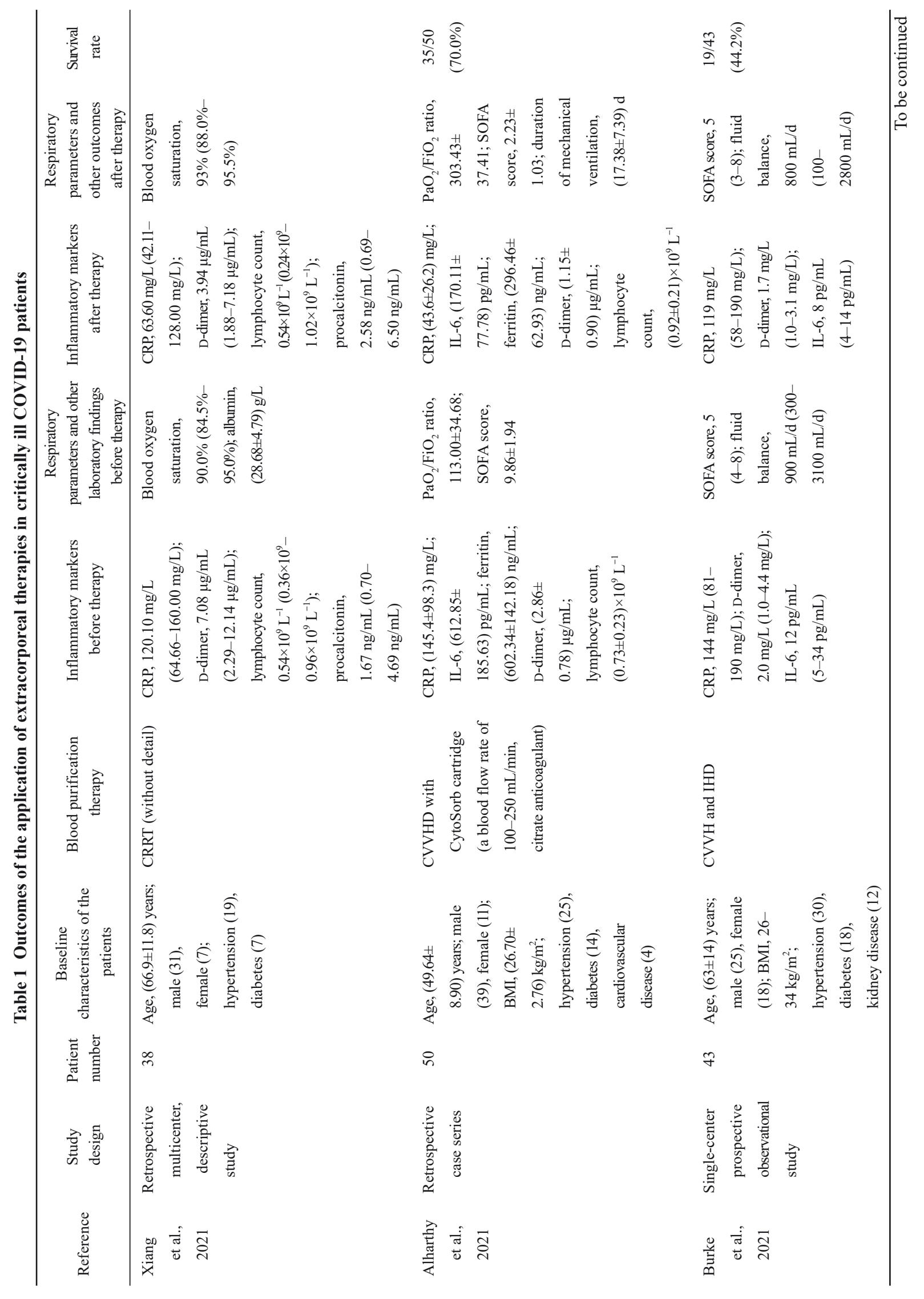




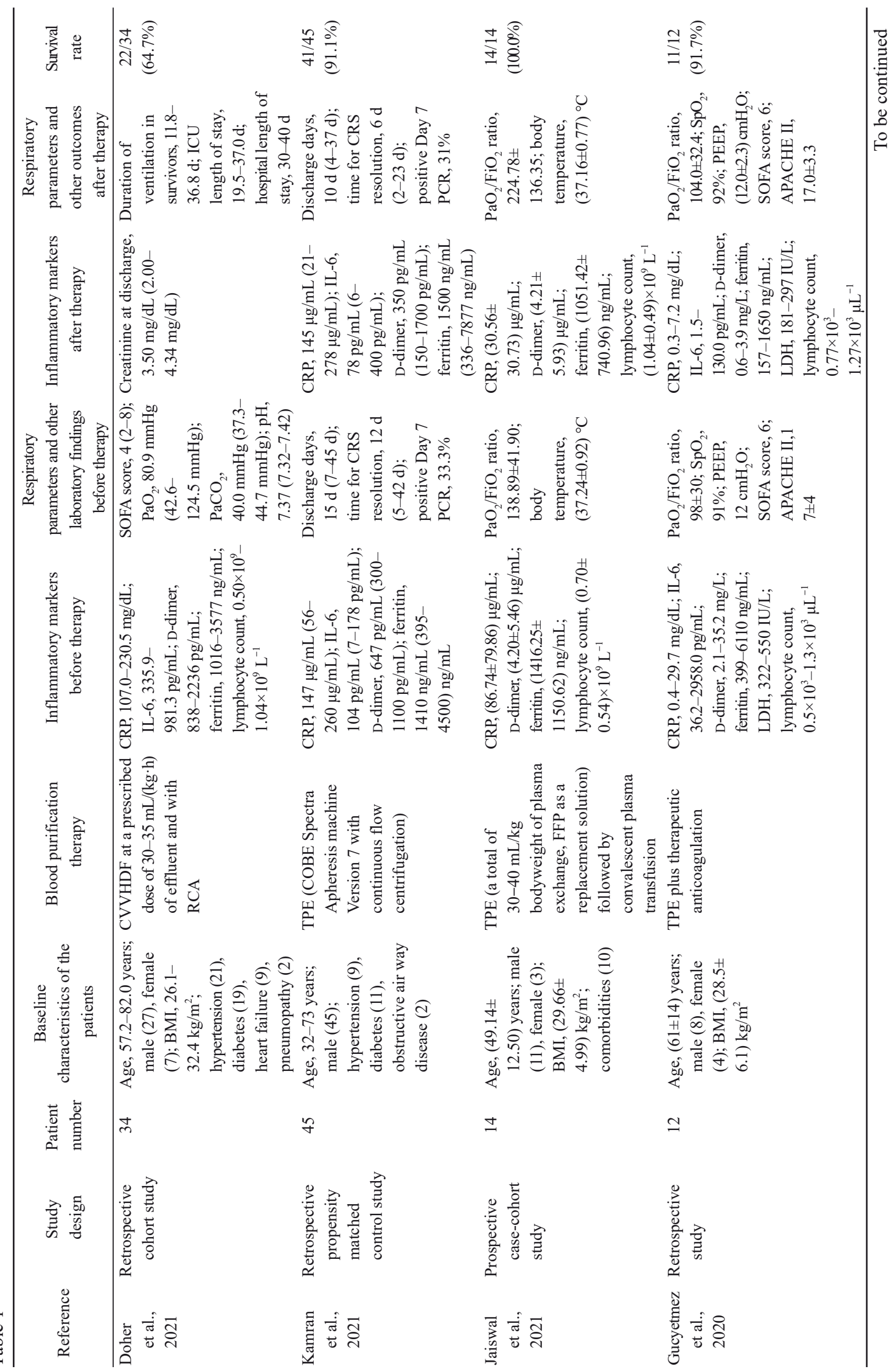




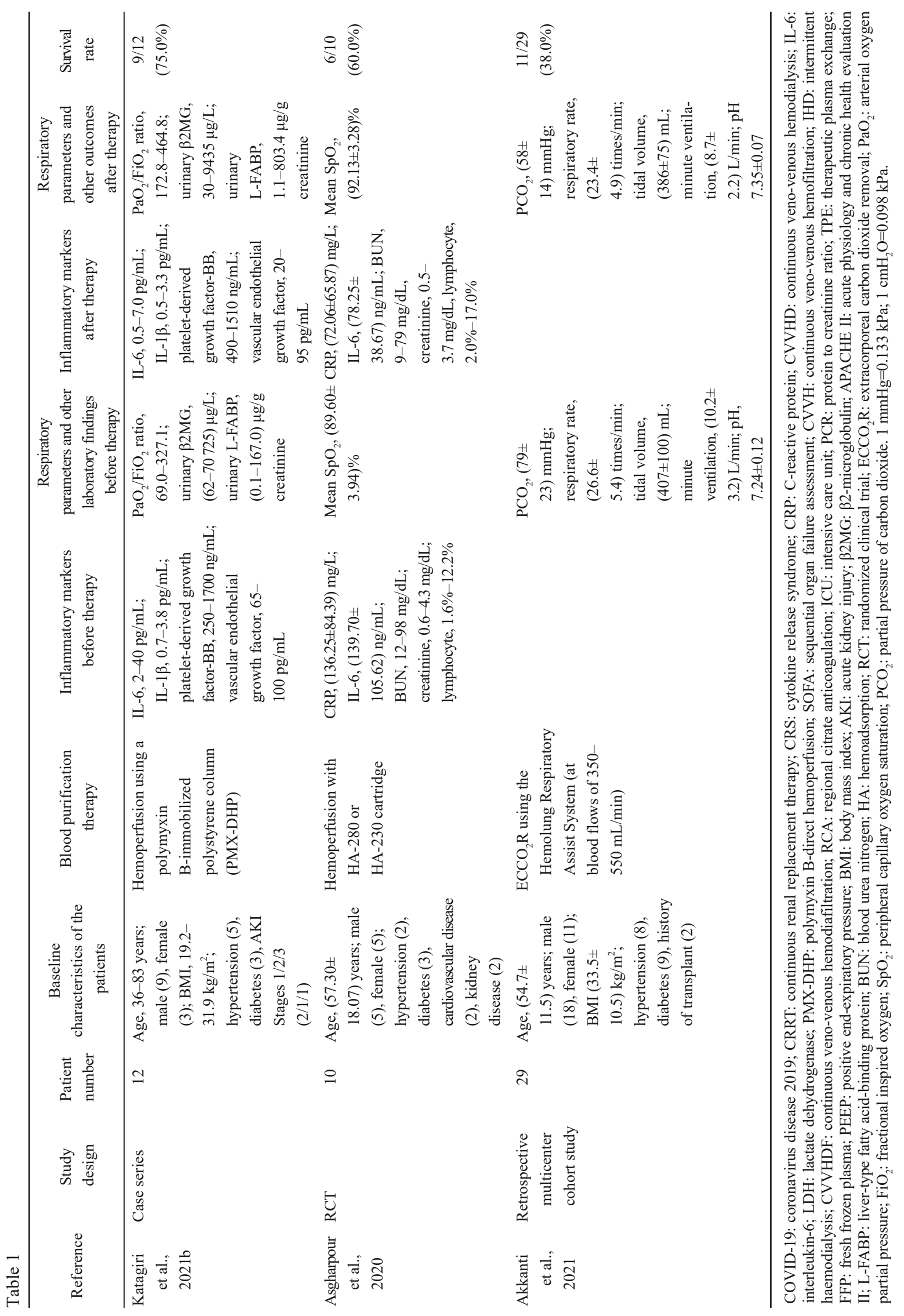


Table 2 Advantages and limitations of some extracorporeal therapies in treating critically ill COVID-19 patients

\begin{tabular}{|c|c|c|}
\hline $\begin{array}{c}\text { Blood purification } \\
\text { therapy }\end{array}$ & Advantage & Limitation \\
\hline CRRT & $\begin{array}{l}\text { Eliminates toxic substances, inflammatory } \\
\text { mediators, and inflammatory cytokines. } \\
\text { CRRT-induced low temperature can reduce the } \\
\text { production of } \mathrm{CO}_{2} \text {. } \\
\text { Reduces lung-kidney interaction. } \\
\text { Does not easily cause hemodynamic changes, and } \\
\text { can achieve the goal of fluid balance with higher } \\
\text { hemodynamic stability. } \\
\text { CVVHD or CVVHDF modality can reduce the } \\
\text { filtration fraction and protect the life of } \\
\text { cardiopulmonary bypass. }\end{array}$ & $\begin{array}{l}\text { Short supply of CRRT resources in many hospitals. } \\
\text { The need for intense nursing care requires a large } \\
\text { number of nursing staff. } \\
\text { Increased frequency of circuit clotting. } \\
\text { Loss of trace elements; catheter-related infection. } \\
\text { Patients need anticoagulation therapy. } \\
\text { The timing and treatment dose of CRRT when } \\
\text { treating critically ill COVID-19 patients are } \\
\text { controversial. }\end{array}$ \\
\hline PIRRT & $\begin{array}{l}\text { Can increase patients' coverage of CRRT machines } \\
\text { by allowing several patients treated with the } \\
\text { same machine per day. } \\
\text { Has a low rate of circuit clotting. }\end{array}$ & $\begin{array}{l}\text { Transitory intradialytic hypotension may occur. } \\
\text { A lack of standardized PIRRT prescription } \\
\text { guidelines. } \\
\text { Frequent exchanges of solutions compared to } \\
\text { CRRT to process the same volume of blood. } \\
\text { Variability of drug pharmacokinetics because of } \\
\text { heterogeneity in prescription. }\end{array}$ \\
\hline TPE & $\begin{array}{l}\text { Can remove inflammatory cytokines, stabilize the } \\
\text { endothelial membrane, and reset the } \\
\text { hypercoagulable state. } \\
\text { Can replace the protective factors like protein C, } \\
\text { ADAMTS-13, and angiopoietin- } 1 \text {. }\end{array}$ & $\begin{array}{l}\text { Can remove the neutralizing antibodies against } \\
\text { SARS-CoV-2. } \\
\text { Can block the release of cytokines only temporarily. } \\
\text { Can cause hypocalcemia and anaphylactic shock. }\end{array}$ \\
\hline HP & $\begin{array}{l}\text { Can remove inflammatory cytokines, endotoxins, } \\
\text { DAMPs, and PAMPs. } \\
\text { Can eliminate the toxins associated with acute } \\
\text { liver failure. }\end{array}$ & $\begin{array}{l}\text { Has not yet been formally studied. } \\
\text { Still needs more RCTs. }\end{array}$ \\
\hline ECMO & $\begin{array}{l}\text { Can gain valuable time for the recovery of } \\
\text { cardiopulmonary system. } \\
\text { Some evidence shows an additional survival benefit } \\
\text { with the use of ECMO. }\end{array}$ & $\begin{array}{l}\text { A lack of relevant clinical evidence. The timing, } \\
\text { indications, management, and risks of ECMO are } \\
\text { still controversial. } \\
\text { Needs a lot of medical resources in short supply } \\
\text { during the COVID-19 epidemic. } \\
\text { Complicated treatment process and potential } \\
\text { complications such as fatal bleeding and } \\
\text { infection. }\end{array}$ \\
\hline $\mathrm{ECCO}_{2} \mathrm{R}$ & $\begin{array}{l}\text { Uses lower blood flow rates through smaller } \\
\text { cannula and provides substantial } \mathrm{CO}_{2} \text { elimination. } \\
\text { Simple operation method; single subject can } \\
\text { operate independently. } \\
\text { Lower cost than some extracorporeal life supports } \\
\text { like ECOM. }\end{array}$ & $\begin{array}{l}\text { Weaker oxygenation effect than ECOM; needs to } \\
\text { extend the ventilation time to make up for its } \\
\text { oxygenation effect. }\end{array}$ \\
\hline
\end{tabular}

COVID-19: coronavirus disease 2019; CRRT: continuous renal replacement therapy; PIRRT: prolonged intermittent renal replacement therapy; TPE: therapeutic plasma exchange; HP: hemoperfusion; ECMO: extracorporeal membrane oxygenation; $\mathrm{ECCO}_{2} \mathrm{R}$ : extracorporeal carbon dioxide removal; CVVHD: continuous veno-venous hemodialysis; CVVHDF: continuous veno-venous hemodiafiltration; ADAMTS-13: a disintegrin and metalloproteinase with a thrombospondin type 1 motif, member 13; DAMP: danger-associated molecular pattern; PAMP: pathogen-associated molecular pattern; SARS-CoV-2: severe acute respiratory syndrome coronavirus 2; RCT: randomized clinical trial.

\section{Acknowledgments}

This work was supported by the 1.3.5 Project for Disciplines of Excellence, West China Hospital, Sichuan University (Nos. 2018HXFH018 and ZYGD18027), China.

\section{Author contributions}

Zhifeng ZHOU, Huang KUANG, and Yuexian MA searched the literature; Zhifeng ZHOU and Huang KUANG drafted the manuscript; Ling ZHANG contributed to the design 
and revision of this manuscript. All authors approved the final manuscript.

\section{Compliance with ethics guidelines}

Zhifeng ZHOU, Huang KUANG, Yuexian MA, and Ling ZHANG declare that they have no conflict of interest.

This article does not contain any studies with human or animal subjects performed by any of the authors.

\section{References}

Adapa S, Aeddula NR, Konala VM, et al., 2020. COVID-19 and renal failure: challenges in the delivery of renal replacement therapy. J Clin Med Res, 12(5):276-285. https://doi.org/10.14740/jocmr4160

Adeli SH, Asghari A, Tabarraii R, et al., 2020. Therapeutic plasma exchange as a rescue therapy in patients with coronavirus disease 2019: a case series. Pol Arch Intern Med, 130(5):455-458. https://doi.org/10.20452/pamw.15340

Akkanti B, Jagpal S, Darwish R, et al., 2021. Physiologic improvement in respiratory acidosis using extracorporeal $\mathrm{CO}_{2}$ removal with hemolung respiratory assist system in the management of severe respiratory failure from coronavirus disease 2019. Crit Care Explor, 3(3): 0372. https://doi.org/10.1097/cce.0000000000000372

Al-Fares A, Pettenuzzo T, del Sorbo L, 2019. Extracorporeal life support and systemic inflammation. Intens Care Med $\operatorname{Exp}, 7(\mathrm{~S} 1): 46$. https://doi.org/10.1186/s40635-019-0249-y

Alharthy A, Faqihi F, Memish ZA, et al., 2021. Continuous renal replacement therapy with the addition of cytosorb cartridge in critically ill patients with COVID-19 plus acute kidney injury: a case-series. Artif Organs, 45(5): E101-E112. https://doi.org/10.1111/aor.13864

Asgharpour M, Mehdinezhad H, Bayani M, et al., 2020. Effectiveness of extracorporeal blood purification (hemoadsorption) in patients with severe coronavirus disease 2019 (COVID-19). BMC Nephrol, 21:356. https://doi.org/10.1186/s12882-020-02020-3

Atan R, Peck LC, Prowle J, et al., 2018. A double-blind randomized controlled trial of high cutoff versus standard hemofiltration in critically ill patients with acute kidney injury. Crit Care Med, 46(10):e988-e994. https://doi.org/10.1097/ccm.0000000000003350

Attallah N, Gupta S, Madhyastha R, et al., 2021. Anticoagulation in COVID-19 patients requiring continuous renal replacement therapy. Anaesth Crit Care Pain Med, 40(3): 100841. https://doi.org/10.1016/j.accpm.2021.100841

Azoulay E, Zafrani L, Mirouse A, et al., 2020. Clinical phenotypes of critically ill COVID-19 patients. Intensive Care Med, 46:1651-1652. https://doi.org/10.1007/s00134-020-06120-4

Berhés M, Fábián Á, László I, et al., 2020. Organ replacement therapy and life-supporting treatment modalities in critically ill COVID-19 patients. Orv Hetil, 161(17):704-709. https://doi.org/10.1556/650.2020.31813
Bhatraju PK, Ghassemieh BJ, Nichols M, et al., 2020. COVID-19 in critically ill patients in the seattle region-case series. N Engl J Med, 382(21):2012-2022. https://doi.org/10.1056/NEJMoa2004500

Burke E, Haber E, Pike CW, et al., 2021. Outcomes of renal replacement therapy in the critically ill with COVID-19. Med Intensiva, 45(6):325-331. https://doi.org/10.1016/j.medin.2021.02.004

Camboni D, Philip A, Schmid C, et al., 2019. Double, triple and quadruple cannulation for veno-arterial extracorporeal membrane oxygenation support: is there a limit? Ann Cardiothorac Surg, 8(1):151-159. https://doi.org/10.21037/acs.2019.01.03

Capone S, Abramyan S, Ross B, et al., 2020. Characterization of critically ill COVID-19 patients at a Brooklyn safety-net hospital. Cureus, 12(8):e9809. https://doi.org/10.7759/cureus.9809

Cha RH, Joh JS, Jeong I, et al., 2015. Renal complications and their prognosis in Korean patients with middle east respiratory syndrome-coronavirus from the central MERSCoV designated hospital. J Korean Med Sci, 30(12): 1807-1814. https://doi.org/10.3346/jkms.2015.30.12.1807

Chen Y, Wang SH, Huang JR, et al., 2021. Application of extracorporeal carbon dioxide removal combined with continuous blood purification therapy in ARDS with hypercapnia in patients with critical COVID-19. Clin Hemorheol Microcirc, 78(2):199-207. https://doi.org/10.3233/ch-201080

Cheng YC, Luo R, Wang K, et al., 2020. Kidney disease is associated with in-hospital death of patients with COVID-19. Kidney Int, 97(5):829-838. https://doi.org/10.1016/j.kint.2020.03.005

Chinese Society of Nephrology, Professional Committee of Nephrology, 2020. Expert consensus on special blood purification technics in patients with corona virus disease 2019. Chin J Intern Med, 59(11):847-853 (in Chinese). https://doi.org/10.3760/cma.j.cn112138-20200306-00202

Chua HR, MacLaren G, Choong LHL, et al., 2020. Ensuring sustainability of continuous kidney replacement therapy in the face of extraordinary demand: lessons from the COVID-19 pandemic. Am J Kidney Dis, 76(3):392-400. https://doi.org/10.1053/j.ajkd.2020.05.008

Colaneri M, Valsecchi P, Perotti L, et al., 2020. Running out of bullets: the challenging management of acute hepatitis and SARS-COV-2 from the SMatteo COvid19 Registry (SMACORE). Liver Int, 40(11):2655-2659. https://doi.org/10.1111/liv.14609

Combes A, Schmidt M, Hodgson CL, et al., 2020. Extracorporeal life support for adults with acute respiratory distress syndrome. Intensive Care Med, 46:2464-2476. https://doi.org/10.1007/s00134-020-06290-1

Daoud AM, Soliman KM, Ali HK, 2021. Potential limitations of plasmapheresis in treatment of COVID-19 patients: how to overcome them? Ther Apher Dial, 25(3):350. https://doi.org/10.1111/1744-9987.13568

Dastan F, Saffaei A, Mortazavi SM, et al., 2020. Continues renal replacement therapy (CRRT) with disposable hemoperfusion cartridge: a promising option for severe COVID-19. J Glob Antimicrob Resist, 21:340-341. 
https://doi.org/10.1016/j.jgar.2020.04.024

Deep A, Bansal M, Ricci Z, 2021. Acute kidney injury and special considerations during renal replacement therapy in children with coronavirus disease-19: perspective from the critical care nephrology section of the European Society of Paediatric and Neonatal Intensive Care. Blood Purif, 50(2):150-160. https://doi.org/10.1159/000509677

Diamanti AP, Rosado MM, Pioli C, et al., 2020. Cytokine release syndrome in COVID-19 patients, a new scenario for an old concern: the fragile balance between infections and autoimmunity. Int J Mol Sci, 21(9):3330. https://doi.org/10.3390/ijms21093330

Din MAU, Boppana LKT, 2020. An update on the 2019nCoV outbreak. Am J Infect Control, 48(6):713. https://doi.org/10.1016/j.ajic.2020.01.023

Doher MP, de Carvalho FRT, Scherer PF, et al., 2021. Acute kidney injury and renal replacement therapy in critically ill COVID-19 patients: risk factors and outcomes: a singlecenter experience in Brazil. Blood Purif, 50(4-5):520-530. https://doi.org/10.1159/000513425

Dong MZ, Zhang J, Ma XF, et al., 2020. ACE2, TMPRSS2 distribution and extrapulmonary organ injury in patients with COVID-19. Biomed Pharmacother, 131:110678. https://doi.org/10.1016/j.biopha.2020.110678

Faqihi F, Alharthy A, Alodat M, et al., 2020. Therapeutic plasma exchange in adult critically ill patients with life-threatening SARS-CoV-2 disease: a pilot study. J Crit Care, 60:328333. https://doi.org/10.1016/j.jcrc.2020.07.001

Fardet L, Fève B, 2014. Systemic glucocorticoid therapy: a review of its metabolic and cardiovascular adverse events. Drugs, 74(15):1731-1745. https://doi.org/10.1007/s40265-014-0282-9

Fayad AI, Buamscha DG, Ciapponi A, 2016. Intensity of continuous renal replacement therapy for acute kidney injury. Cochrane Database Syst Rev, 10(10):CD010613. https://doi.org/10.1002/14651858.CD010613.pub2

Fernandez J, Gratacos-Ginès J, Olivas P, et al., 2020. Plasma exchange: an effective rescue therapy in critically ill patients with coronavirus disease 2019 infection. Crit Care Med, 48(12):e1350-e1355. https://doi.org/10.1097/ccm.0000000000004613

Fu D, Yang B, Xu J, et al., 2020. COVID-19 infection in a patient with end-stage kidney disease. Nephron, 144(5): 245-247. https://doi.org/10.1159/000507261

García LF, 2020. Immune response, inflammation, and the clinical spectrum of COVID-19. Front Immunol, 11:1441. https://doi.org/10.3389/fimmu.2020.01441

Grazioli A, Athale J, Tanaka K, et al., 2020. Perioperative applications of therapeutic plasma exchange in cardiac surgery: a narrative review. J Cardiothorac Vasc Anesth, 34(12):3429-3443. https://doi.org/10.1053/j.jvca.2020.01.054

Guan WJ, Ni ZY, Hu Y, et al., 2020. Clinical characteristics of coronavirus disease 2019 in China. N Engl J Med, 382(18): 1708-1720.

https://doi.org/10.1056/NEJMoa2002032

Gucyetmez B, Atalan HK, Sertdemir I, et al., 2020. Therapeutic plasma exchange in patients with COVID-19 pneumonia in intensive care unit: a retrospective study. Crit Care, 24:492.

https://doi.org/10.1186/s13054-020-03215-8

Haase M, Bellomo R, Baldwin I, et al., 2007. Hemodialysis membrane with a high-molecular-weight cutoff and cytokine levels in sepsis complicated by acute renal failure: a phase 1 randomized trial. Am J Kidney Dis, 50(2):296-304. https://doi.org/10.1053/j.ajkd.2007.05.003

Hazzard I, Jones S, Quinn T, 2015. Coupled plasma haemofiltration filtration in severe sepsis: systematic review and meta-analysis. J R Army Med Corps, 161(S1):i17-i22. https://doi.org/10.1136/jramc-2015-000552

Hoffmann M, Kleine-Weber H, Schroeder S, et al., 2020. SARS-CoV-2 cell entry depends on ACE2 and TMPRSS2 and is blocked by a clinically proven protease inhibitor. Cell, 181(2):271-280.e8. https://doi.org/10.1016/j.cell. 2020.02.052

Honore PM, Mugisha A, Kugener L, et al., 2020. Therapeutic plasma exchange as a routine therapy in septic shock and as an experimental treatment for COVID-19: we are not sure. Crit Care, 24:226. https://doi.org/10.1186/s13054-020-02943-1

Huang CL, Wang YM, Li XW, et al., 2020. Clinical features of patients infected with 2019 novel coronavirus in Wuhan, China. Lancet, 395(10223):497-506. https://doi.org/10.1016/s0140-6736(20)30183-5

Husain-Syed F, Birk HW, Wilhelm J, et al., 2020. Extracorporeal carbon dioxide removal using a renal replacement therapy platform to enhance lung-protective ventilation in hypercapnic patients with coronavirus disease 2019associated acute respiratory distress syndrome. Front Med, 7:598379. https://doi.org/10.3389/fmed.2020.598379

Izda V, Jeffries MA, Sawalha AH, 2021. COVID-19: a review of therapeutic strategies and vaccine candidates. Clin Immunol, 222:108634. https://doi.org/10.1016/j.clim.2020.108634

Jaiswal V, Nasa P, Raouf M, et al., 2021. Therapeutic plasma exchange followed by convalescent plasma transfusion in critical COVID-19-an exploratory study. Int $J$ Infect Dis, 102:332-334. https://doi.org/10.1016/j.ijid.2020.10.085

Jin YH, Cai L, Cheng ZS, et al., 2020. A rapid advice guideline for the diagnosis and treatment of 2019 novel coronavirus (2019-nCoV) infected pneumonia (standard version). Mil Med Res, 7:4.

https://doi.org/10.1186/s40779-020-0233-6

Joannes-Boyau O, Honoré PM, Perez P, et al., 2013. Highvolume versus standard-volume haemofiltration for septic shock patients with acute kidney injury (IVOIRE study): a multicentre randomized controlled trial. Intensive Care Med, 39:1535-1546. https://doi.org/10.1007/s00134-013-2967-z

Jonckheer J, Spapen H, Debain A, et al., 2019. $\mathrm{CO}_{2}$ and $\mathrm{O}_{2}$ removal during continuous veno-venous hemofiltration: a pilot study. BMC Nephrol, 20:222. https://doi.org/10.1186/s12882-019-1378-y

Kade G, Spaleniak S, Antosiewicz S, 2020. Continuous renal replacement therapy as a treatment of selected acute 
intoxications. Pol Merkur Lekarski, 49(286):250-254.

Kamran SM, Mirza ZEH, Naseem A, et al., 2021. Therapeutic plasma exchange for coronavirus disease-2019 triggered cytokine release syndrome; a retrospective propensity matched control study. PLOS ONE, 16(1):e0244853. https://doi.org/10.1371/journal.pone.0244853

Katagiri D, Ishikane M, Ogawa T, et al., 2021a. Continuous renal replacement therapy for a patient with severe COVID-19. Blood Purif, 50(1):129-131. https://doi.org/10.1159/000508062

Katagiri D, Ishikane M, Asai Y, et al., 2021b. Direct hemoperfusion using a polymyxin B-immobilized polystyrene column for COVID-19. J Clin Apher, 36(3):313-321. https://doi.org/10.1002/jca.21861

Khamis F, Al-Zakwani I, al Hashmi S, et al., 2020. Therapeutic plasma exchange in adults with severe COVID-19 infection. Int J Infect Dis, 99:214-218. https://doi.org/10.1016/j.ijid.2020.06.064

Kox M, Waalders NJB, Kooistra EJ, et al., 2020. Cytokine levels in critically ill patients with COVID-19 and other conditions. JAMA, 324(15):1565-1567. https://doi.org/10.1001/jama.2020.17052

Li L, Li RR, Wu ZX, et al., 2020. Therapeutic strategies for critically ill patients with COVID-19. Ann Intensive Care, 10:45. https://doi.org/10.1186/s13613-020-00661-z

Li Q, Guan XH, Wu P, et al., 2020. Early transmission dynamics in Wuhan, China, of novel coronavirus-infected pneumonia. N Engl J Med, 382(13):1199-1207. https://doi.org/10.1056/NEJMoa2001316

Lin JH, Chen YC, Lu CL, et al., 2020. Application of plasma exchange in association with higher dose CVVH in Cytokine Storm Complicating COVID-19. J Formos Med Assoc, 119(6):1116-1118. https://doi.org/10.1016/j.jfma.2020.04.023

Lu RJ, Zhao X, Li J, et al., 2020. Genomic characterisation and epidemiology of 2019 novel coronavirus: implications for virus origins and receptor binding. Lancet, 395(10224):565-574.

https://doi.org/10.1016/s0140-6736(20)30251-8

Luo S, Yang LJ, Wang C, et al., 2020. Clinical observation of 6 severe COVID-19 patients treated with plasma exchange or tocilizumab. J Zhejiang Univ (Med Sci), 49(2): 227231 (in Chinese). https://doi.org/10.3785/j.issn.1008-9292.2020.03.06

Ma XC, Liang ML, Ding M, et al., 2020. Extracorporeal membrane oxygenation (ECMO) in critically ill patients with coronavirus disease 2019 (COVID-19) pneumonia and acute respiratory distress syndrome (ARDS). Med Sci Monit, 26:e925364.

https://doi.org/10.12659/msm.925364

Mair-Jenkins J, Saavedra-Campos M, Baillie JK, et al., 2015. The effectiveness of convalescent plasma and hyperimmune immunoglobulin for the treatment of severe acute respiratory infections of viral etiology: a systematic review and exploratory meta-analysis. J Infect Dis, 211(1):80-90. https://doi.org/10.1093/infdis/jiu396

Menon R, Otto EA, Sealfon R, et al., 2020. SARS-CoV-2 receptor networks in diabetic and COVID-19 associated kidney disease. Kidney Int, 98(6):1502-1518. https://doi.org/10.1016/j.kint.2020.09.015

Moradi H, Abbasi S, 2020. Hemoperfusion as a supportive treatment in a COVID-19 patient with late pulmonary thromboembolism: a case report. Int Med Case Rep J, 13:341-345. https://doi.org/10.2147/imcrj.S263127

Na KR, Kim HR, Ham Y, et al., 2020. Acute kidney injury and kidney damage in COVID-19 patients. $J$ Korean Med Sci, 35(28):e257.

https://doi.org/10.3346/jkms.2020.35.e257

Nachtigall I, Lenga P, Jóźwiak K, et al., 2020. Clinical course and factors associated with outcomes among 1904 patients hospitalized with COVID-19 in Germany: an observational study. Clin Microbiol Infect, 26(12):1663-1669. https://doi.org/10.1016/j.cmi.2020.08.011

Nadim MK, Forni LG, Mehta RL, et al., 2020. COVID-19associated acute kidney injury: consensus report of the 25th Acute Disease Quality Initiative (ADQI) Workgroup. Nat Rev Nephrol, 16(12):747-764. https://doi.org/10.1038/s41581-020-00356-5

Ñamendys-Silva SA, 2020. ECMO for ARDS due to COVID-19. Heart Lung, 49(4):348-349. https://doi.org/10.1016/j.hrtlng.2020.03.012

Napp LC, Kühn C, Hoeper MM, et al., 2016. Cannulation strategies for percutaneous extracorporeal membrane oxygenation in adults. Clin Res Cardiol, 105(4):283-296. https://doi.org/10.1007/s00392-015-0941-1

Pan PH, Song C, Lu RL, 2020. The timing of continuous renal replacement therapy in severe COVID-19. Chin J Tuberc Respir Dis, 43(9):721-724 (in Chinese). https://doi.org/10.3760/cma.j.cn112147-20200521-00621

Parasher A, 2021. COVID-19: current understanding of its pathophysiology, clinical presentation and treatment. Postgrad Med J, 97(1147):312-320.

https://doi.org/10.1136/postgradmedj-2020-138577

Post A, den Deurwaarder ESG, Bakker SJL, et al., 2020. Kidney infarction in patients with COVID-19. Am J Kidney Dis, 76(3):431-435. https://doi.org/10.1053/j.ajkd.2020.05.004

Pourahmad R, Moazzami B, Rezaei N, 2020. Efficacy of plasmapheresis and immunoglobulin replacement therapy (IVIG) on patients with COVID-19. SN Compr Clin Med, 2(9): 1407-1411. https://doi.org/10.1007/s42399-020-00438-2

Ramirez-Sandoval JC, Gaytan-Arocha JE, Xolalpa-Chávez P, et al., 2021. Prolonged intermittent renal replacement therapy for acute kidney injury in COVID-19 patients with acute respiratory distress syndrome. Blood Purif, 50(3):355-363 https://doi.org/10.1159/000510996

Rampino T, Gregorini M, Perotti L, et al., 2020. Hemoperfusion with cytosorb as adjuvant therapy in critically ill patients with SARS-CoV2 pneumonia. Blood Purif, 50:566-571. https://doi.org/10.1159/000511725

RECOVERY Collaborative Group, 2021. Convalescent plasma in patients admitted to hospital with COVID-19 (RECOVERY): a randomised controlled, open-label, platform trial. Lancet, 397(10289):2049-2059.

https://doi.org/10.1016/s0140-6736(21)00897-7

Ronco C, Belomo R, Homel P, et al., 2002. Effects of different 
doses in continuous veno-venous haemofiltration on outcomes of acute renal failure: a prospective randomised trial. EDTNA-ERCA J, 28(S2):7-12.

https://doi.org/10.1111/j.1755-6686.2002.tb00248.x

Ronco C, Bagshaw SM, Bellomo R, et al., 2021. Extracorporeal blood purification and organ support in the critically ill patient during COVID-19 pandemic: expert review and recommendation. Blood Purif, 50(1):17-27. https://doi.org/10.1159/000508125

Rothan HA, Byrareddy SN, 2020. The epidemiology and pathogenesis of coronavirus disease (COVID-19) outbreak. J Autoimmun, 109:102433. https://doi.org/10.1016/j.jaut.2020.102433

Safari S, Salimi A, Zali A, et al., 2020. Extracorporeal hemoperfusion as a potential therapeutic option for severe COVID-19 patients; a narrative review. Arch Acad Emerg Med, 8(1):e67.

Schefold JC, von Haehling S, Corsepius M, et al., 2007. A novel selective extracorporeal intervention in sepsis. Shock, 28(4):418-425. https://doi.org/10.1097/shk.0b013e31804f5921

Schmidt M, Jaber S, Zogheib E, et al., 2018. Feasibility and safety of low-flow extracorporeal $\mathrm{CO}_{2}$ removal managed with a renal replacement platform to enhance lung-protective ventilation of patients with mild-to-moderate ARDS. Crit Care, 22:122. https://doi.org/10.1186/s13054-018-2038-5

Shen CG, Wang ZQ, Zhao F, et al., 2020. Treatment of 5 critically ill patients with COVID-19 with convalescent plasma. JAMA, 323(16):1582-1589. https://doi.org/10.1001/jama.2020.4783

Shi H, Zhou CM, He PH, et al., 2020. Successful treatment with plasma exchange followed by intravenous immunoglobulin in a critically ill patient with COVID-19. Int $J$ Antimicrob Agents, 56(2):105974. https://doi.org/10.1016/j.ijantimicag.2020.105974

Shi Y, Wang G, Cai XP, et al., 2020. An overview of COVID-19. $J$ Zhejiang Univ-Sci B (Biomed \& Biotechnol), 21(5): 343-360. https://doi.org/10.1631/jzus.B2000083

Smolander J, Bruchfeld A, 2020. COVID-19 and kidney disease. Lakartidningen, 117:20110 (in Swedish).

Stahl K, Schmidt JJ, Seeliger B, et al., 2020a. Effect of therapeutic plasma exchange on endothelial activation and coagulationrelated parameters in septic shock. Crit Care, 24:71. https://doi.org/10.1186/s13054-020-2799-5

Stahl K, Bode C, David S, 2020b. First do no harm-beware the risk of therapeutic plasma exchange in severe COVID-19. Crit Care, 24:363. https://doi.org/10.1186/s13054-020-03070-7

Tandukar S, Palevsky PM, 2019. Continuous renal replacement therapy: who, when, why, and how. Chest, 155(3): 626-638. https://doi.org/10.1016/j.chest.2018.09.004

The RENAL Replacement Therapy Study Investigators, 2009. Intensity of continuous renal-replacement therapy in critically ill patients. $N$ Engl J Med, 361(17):1627-1638. https://doi.org/10.1056/NEJMoa0902413

The VA/NIH Acute Renal Failure Trial Network, 2008. Intensity of renal support in critically ill patients with acute kidney injury. $N$ Engl J Med, 359(1):7-20.

https://doi.org/10.1056/NEJMoa0802639

Tully RP, Hopley N, Lawrence G, 2020. The successful use of extracorporeal carbon dioxide removal as a rescue therapy in a patient with severe COVID-19 pneumonitis. Anaesth Rep, 8(2):113-115.

https://doi.org/10.1002/anr3.12072

Vardanjani AE, Ronco C, Rafiei H, et al., 2021. Early hemoperfusion for cytokine removal may contribute to prevention of intubation in patients infected with COVID-19. Blood Purif, 50(2):257-260. https://doi.org/10.1159/000509107

Varga Z, Flammer AJ, Steiger P, et al., 2020. Endothelial cell infection and endotheliitis in COVID-19. Lancet, 395(10234):1417-1418. https://doi.org/10.1016/s0140-6736(20)30937-5

Velavan TP, Meyer CG, 2020. The COVID-19 epidemic. Trop Med Int Health, 25(3):278-280. https://doi.org/10.1111/tmi.13383

Villa G, Chelazzi C, Morettini E, et al., 2017. Organ dysfunction during continuous veno-venous high cut-off hemodialysis in patients with septic acute kidney injury: a prospective observational study. PLoS ONE, 12(2):e0172039. https://doi.org/10.1371/journal.pone.0172039

Volbeda M, Londema M, van Meurs M, et al., 2020. A method to improve continuous renal replacement therapy circuit survival time in critically ill coronavirus disease 2019 patients with acute kidney injury. Crit Care Explor, 2(10): $\mathrm{e} 0258$. https://doi.org/10.1097/cce.0000000000000258

Wang P, Sha J, Meng M, et al., 2020. Risk factors for severe COVID-19 in middle-aged patients without comorbidities: a multicentre retrospective study. J Transl Med, 18:461. https://doi.org/10.1186/s12967-020-02655-8

Wang Y, Jiang WW, He Q, et al., 2020. A retrospective cohort study of methylprednisolone therapy in severe patients with COVID-19 pneumonia. Sig Transduct Target Ther, 5:57. https://doi.org/10.1038/s41392-020-0158-2

Weidhase L, Haussig E, Haussig S, et al., 2019. Middle molecule clearance with high cut-off dialyzer versus high-flux dialyzer using continuous veno-venous hemodialysis with regional citrate anticoagulation: a prospective randomized controlled trial. PLoS ONE, 14(4):e0215823. https://doi.org/10.1371/journal.pone.0215823

Wu CM, Chen XY, Cai YP, et al., 2020. Risk factors associated with acute respiratory distress syndrome and death in patients with coronavirus disease 2019 pneumonia in Wuhan, China. JAMA Intern Med, 180(7):934-943. https://doi.org/10.1001/jamainternmed.2020.0994

Wu HJ, Larsen CP, Hernandez-Arroyo CF, et al., 2020. AKI and collapsing glomerulopathy associated with COVID-19 and APOL1 high-risk genotype. J Am Soc Nephrol, 31(8): 1688-1695. https://doi.org/10.1681/asn.2020050558

Wu Z, Zhang Q, Ye G, et al., 2021. Structural and physiological changes of the human body upon SARS-CoV-2 infection. $J$ Zhejiang Univ-Sci B (Biomed \& Biotechnol), 22(4): 
310-317.

https://doi.org/10.1631/jzus.B2000523

Wu ZY, McGoogan JM, 2020. Characteristics of and important lessons from the coronavirus disease 2019 (COVID-19) outbreak in China: summary of a report of 72314 cases from the Chinese Center for Disease Control and Prevention. JAMA, 323(13):1239-1242.

https://doi.org/10.1001/jama.2020.2648

Xiang HL, Song B, Zhang YY, et al., 2021. The effectiveness of continuous renal replacement therapy in critical COVID-19 patients with cytokine release syndrome: a retrospective, multicenter, descriptive study from Wuhan, China. Aging, 13(7):9243-9252

https://doi.org/10.18632/aging.202838

Yang XB, Yu Y, Xu JQ, et al., 2020. Clinical course and outcomes of critically ill patients with SARS-CoV-2 pneumonia in Wuhan, China: a single-centered, retrospective, observational study. Lancet Respir Med, 8(5):475-481. https://doi.org/10.1016/s2213-2600(20)30079-5

Yang Y, Shi J, Ge S, et al., 2020. Association between prolonged intermittent renal replacement therapy and all-cause mortality in COVID-19 patients undergoing invasive mechanical ventilation: a retrospective cohort study. Blood Purif, 50(4-5):481-488. https://doi.org/10.1159/000512099

Yessayan LT, Heung M, Girard FA, et al., 2021. Deployment of a new CRRT/PIRRT device during the COVID-19 pandemic emergency: organizational challenges and implementation results. Blood Purif, 50(3):390-398. https://doi.org/10.1159/000511726

Yiğenoğlu TN, Ulas T, Dal MS, et al., 2020. Extracorporeal blood purification treatment options for COVID-19: the role of immunoadsorption. Transfus Apher Sci, 59(4):102855. https://doi.org/10.1016/j.transci.2020.102855

You B, Zhang YL, Luo GX, et al., 2018. Early application of continuous high-volume haemofiltration can reduce sepsis and improve the prognosis of patients with severe burns. Crit Care, 22:173.

https://doi.org/10.1186/s13054-018-2095-9

Zachariah U, Nair SC, Goel A, et al., 2020. Targeting raised von Willebrand factor levels and macrophage activation in severe COVID-19: consider low volume plasma exchange and low dose steroid. Thromb Res, 192:2. https://doi.org/10.1016/j.thromres.2020.05.001

Zarbock A, Kellum JA, Schmidt C, et al., 2016. Effect of early vs delayed initiation of renal replacement therapy on mortality in critically ill patients with acute kidney injury: the ELAIN randomized clinical trial. JAMA, 315(20): 2190-2199. https://doi.org/10.1001/jama.2016.5828

Zhao J, Cui W, Tian BP, 2020. Efficacy of tocilizumab treatment in severely ill COVID-19 patients. Crit Care, 24:524. https://doi.org/10.1186/s13054-020-03224-7

Zhou F, Yu T, Du RH, et al., 2020. Clinical course and risk factors for mortality of adult inpatients with COVID-19 in Wuhan, China: a retrospective cohort study. Lancet, 395(10229):1054-1062. https://doi.org/10.1016/s0140-6736(20)30566-3

Zou H, Li SQ, 2020. ECMO/CRRT combined support in the treatment of critically ill patients with novel coronavirus pneumonia. Eur Heart J-Case Rep, 4(FI1):1-3. https://doi.org/10.1093/ehjcr/ytaa247 